\title{
A NOTE ON MORPHOMETRY OF TADPOLE AND ADULT OF MICROHYLA ORNATA (DUMÉRIL \& BIBRON) (ANURA: MICROHYLIDAE)
}

\author{
Mithra Dey ${ }^{1}$ and Abhik Gupta \\ Department of Ecology, Assam University, Silchar, Assam 788 011, India. \\ ${ }^{1}$ Email: mithradey@ rediffmail.com
}

\begin{abstract}
The morphometry of the tadpole of Microhyla ornata (Duméril \& Bibron) including morphometric measurements of adult, in addition to those made by earlier studies, were carried out in and around Silchar, Assam. These measurements were made in four developmental stages of tadpoles and in froglet and adult, with notes on their ecology. The morphological and morphometric changes associated with growth and metamorphosis and their possible adaptational significance are discussed.
\end{abstract}

\section{Keywords}

Microhyla ornata, tadpole, froglet, adult, morphometry

\section{Abbreviations}

AU - Assam University; BD - Body depth; BTMH Basal tail musculature height; BW - Body width; BWM - Maximum body width; BWV - Body width at vent; E Eye diameter; E-N - Eye-naris distance; F - Femur length; FL - Forelimb length; Ft - Foot length; $\mathrm{H}$ - Head width; HL - Head length; I-N - Internarial distance; I-O Interorbital distance; S-N - Snout-naris distance; S-O Snout-orbit distance; SV - Snout vent length; T - Tail length (in froglets only); Tb - Tibia length; TH - Tail height; TL - Total length; Ty - Tympanus diameter.

\section{Introduction}

Microhyla ornata was first recorded from the Malabar Coast of southern India (Duméril \& Bibron, 1841), and subsequently from Sri Lanka, China, Meghalaya and Mizoram besides various other parts of India (Thurston, 1888; Fergusson,1904; McCann, 1940; Pillai \& Chanda, 1981; Chanda, 1994). The present study records the occurrence of $M$. ornata in and around Silchar, Cachar District, and in Katlicherra, Hailakandi District, Assam and describes the morphometry of its tadpole. Furthermore several morphometric measurements of adults in addition to those made by earlier studies (Pillai \& Chanda, 1981; Chanda, 1994) are also made, along with brief notes on its ecology.

\section{Materials and Methods}

Adults were caught on sighting and preserved in $6 \%$ formalin solution. Tadpoles were caught by a dip net, a few preserved in formalin, while the rest were reared to metamorphosis to obtain froglets. Tadpoles were given algae and soft water plants like water hyacinth as food in the laboratory. Morphometric measurements were made with a vernier calliper, a mm ruler, and/or an ocular micrometer fitted to a dissecting microscope.

Measurements of tadpoles, froglets and adults were based on existing studies (Tyler, 1968; Altig, 1970; McDonald \& Davies 1990; Meyer, 1991; Davies \& Watson 1994) while a few measurement and ratios were added by us. A total of six developmental stages were measured: tadpoles without limbs (Gosner stage 21-25); with limbs emerging (stage 26-29); with two fully grown limbs (stage 29-34); with four limbs (stage 3539); froglet and adult. Identification of froglets and adults were confirmed with the help of the Zoological Survey of India, Kolkata.

\section{Results and Discussion \\ Ecology}

Both tadoles and adults were collected from Meherpur and Assam University (AU) campus at Dargakona, in and around Silchar ( $\left.24^{\circ} 50^{\prime} \mathrm{N}, 92^{\circ} 51^{\prime} \mathrm{E}\right)$, Cachar District, and from Katlicherra $\left(24^{0} 28^{\prime} \mathrm{N}, 92^{0} 32^{\prime} \mathrm{E}\right)$, Hailakandi District, Assam. The adult is typically terrestrial, nocturnal and rare. It was observed to breed in both temporary and permanent freshwater systems located away from human habitation. In Katlicherra, tadpoles were found in a shallow ditch by a paddy field, in AU campus Dargakona from a temporary pool inside the forest, and in Meherpur, Silchar, from a well and a permanent pond. In AU campus Dargakona, the adults were observed to avoid 
permanent systems nearby, and instead chose a temporary pool for breeding during two successive years of observation in 1997 and 1998. In this system, tadpoles of M. ornata were found to be sympatric with those of Fejervarya limnocharis, while in the permanent pond in Meherpur, it co-existed with Hoplobatrachus tigerinus tadpoles, although the latter occupied deeper areas. M. ornata tadpoles were extremely delicate and suffered heavy mortality during transportation to the laboratory. The froglets upon metamorphosis left water immediately, and could jump up to a height of about $10 \mathrm{~cm}$ to stick to the walls of the plastic container in which they were reared.

\section{Morphology and morphometry of tadpoles}

The tadpoles are white to pale cream in colour, and transparent with melanophore deposition on the forsum, tail and tail fins. The snout is broadly rounded, eyes lateral with naris nearer to the eye than to the tip of the snout. The vent tube is median. The intestine and the blood-filled heart are clearly visible in a transparent body. The mouth is terminal in position and does not possess jaws. The tail is transparent with a caudal and a dorsal fin, and the tail tip is subacuminate. The morphometry of tadpoles of different stages is shown in Table 1. The different morphometric variables show specific increasing or decreasing patterns in different stages. While SV recorded a consistent increase, TL decreases from two limb to four limb stage due to decrease in tail length. When $\mathrm{BW}, \mathrm{BD}$ and $\mathrm{BW} / \mathrm{BD}$ ratios are examined, it may be seen that from a dorso-ventrally flattened body in tadpoles without limb, the tadpole becomes increasingly laterally compressed in the two limb stage, and then again dorso-ventrally flattened in the four limb stage. The tail height is maximum in the two limb stage, while oral aperture diameter shows a consistent increase. The lengths of femur, tibia and foot also increase from two to four limb stage (Table 1).

\section{Morphometry of froglet and adult}

Besides obvious increase in morphometric parameters like SV etc., certain other changes are also noticed. The head becomes relatively broader and shorter in the adult, as revealed by decreasing HL:HW and HL:SV ratios. The tibia as well as the forelimb become proportionately much longer in adults as shown by a sharp increase in Tb:SV and FL:SV ratios. It may

Table 1. Morphometric measurements (in $\mathrm{mm}$ ) of the tadpoles of Microhyla ornata in different development stages ( $X \pm S D$; range in parenthesis)

\begin{tabular}{|c|c|c|c|c|}
\hline Parameters & $\begin{array}{l}\text { G.S.* } 21-25 \\
\text { No } \operatorname{limb}\end{array}$ & $\begin{array}{c}\text { G.S.* } 26-29 \\
\text { Limbs emerging }\end{array}$ & $\begin{array}{l}\text { G.S.* 29-34 } \\
2 \text { limb }\end{array}$ & $\begin{array}{l}\text { G.S.* } 34-39 \\
4 \operatorname{limb}\end{array}$ \\
\hline SV & $3.07 \pm 1.82(2.25-6.35)$ & $6.45 \pm 0.7(6.0-7.0)$ & $6.55 \pm 0.37(6.0-7.5)$ & $7.24 \pm 1.61(6.0-9.0)$ \\
\hline $\mathrm{TL}$ & $6.9 \pm 3.63(5.1-13.4)$ & $16.5 \pm 1.73(15.0-19.0)$ & $18.3 \pm 1.2(17.0-20.0)$ & $14.7 \pm 3.5(13.0-21.0)$ \\
\hline BW & $2.38 \pm 1.3(1.64-4.7)$ & $3.98 \pm 0.64(3.52-4.9)$ & $3.7 \pm 0.57(3.0-4.5)$ & $3.94 \pm 0.96(3.29-5.64)$ \\
\hline$B D$ & $1.48 \pm 1.13(0.9-3.5)$ & $3.2 \pm 0.53(2.9-3.5)$ & $4.28 \pm 0.46(3.9-5.0)$ & $3.0 \pm 0.3(2.7-3.5)$ \\
\hline I-O & $1.36 \pm 0.95(0.94-3.05)$ & $2.93 \pm 0.17(2.82-3.05)$ & $2.36 \pm 0.36(2.1-2.97)$ & $2.44 \pm 0.69(1.41-3.29)$ \\
\hline $\mathrm{I}-\mathrm{N}$ & $0.48 \pm 0.12(0.37-0.7)$ & $0.91 \pm 0.05(0.85-0.94)$ & $0.53 \pm 0.06(0.44-0.61)$ & $1.0 \pm 0.1(0.94-1.17)$ \\
\hline $\mathrm{S}-\mathrm{O}$ & $0.88 \pm 0.55(0.61-1.88)$ & $1.9 \pm 0.05(1.88-1.97)$ & $1.54 \pm 0.13(1.43-1.76)$ & $2.11 \pm 0.52(1.17-2.72)$ \\
\hline S-N & $0.38 \pm 0.31(0.23-0.94)$ & $0.91 \pm 0.05(0.85-0.94)$ & $1.05 \pm 0.17(0.88-1.32)$ & $0.94 \pm 0.33(0.47-1.41)$ \\
\hline $\mathrm{T}$ & $3.83 \pm 1.81(2.91-7.05)$ & $10.2 \pm 1.02(9.0-11.5)$ & $11.75 \pm 1.11(10.5-13.25)$ & $7.46 \pm 2.8(4.0-12.0)$ \\
\hline ВTMH & $0.55 \pm 0.21(0.42-0.94)$ & $0.85 \pm 0.22(0.71-1.17)$ & $2.20 \pm 0.27(2.0-2.5)$ & $1.1 \pm 0.21(2.94-1.41)$ \\
\hline $\mathrm{TH}$ & $1.21 \pm 1.16(0.61-3.29)$ & $1.8 \pm 1.59(0.94-4.23)$ & $3.6 \pm 0.22(3.5-4.0)$ & $2.29 \pm 1.45(1.5-4.46)$ \\
\hline $\mathrm{OA}$ & $0.26 \pm 0.11(0.89-0.47)$ & $0.49 \pm 0.05(0.47-0.56)$ & $0.53 \pm 0.09(0.44-0.66)$ & $0.59 \pm 0.07(0.56-0.7)$ \\
\hline $\mathrm{TD}$ & $1.72 \pm 0.61(1.41-2.82)$ & $2.66 \pm 0.42(2.32-3.29)$ & $1.14 \pm 0.17(0.88-1.32)$ & $3.14 \pm 0.59(2.82-4.04)$ \\
\hline $\mathrm{F}$ & - & - & $1.6 \pm 0.22(1.5-2.0)$ & $2.25 \pm 0.35(1.97-2.82)$ \\
\hline $\mathrm{Tb}$ & - & - & $2.0 \pm 0.31(1.75-2.5)$ & $2.51 \pm 0.59(2.11-3.52)$ \\
\hline $\mathrm{Ft}$ & - & - & $2.45 \pm 0.45(2.0-3.0)$ & $3.31 \pm 0.78(2.82-4.7)$ \\
\hline $\mathrm{FL}$ & - & - & - & $1.86 \pm 0.25(1.6-2.16)$ \\
\hline $\mathrm{Bw} / \mathrm{BD}$ & $1.79 \pm 0.17(1.57-1.98)$ & $1.24 \pm 0.03(1.21-1.29)$ & $0.87 \pm 0.17(0.7-1.15)$ & $1.3 \pm 0.18(1.1-1.61)$ \\
\hline
\end{tabular}

* Gosner stage 
be noted that although the femur also becomes proportionately longer, the increase in hind limb length is contributed more by a sharp increase in tibial length. The body becomes more spindle-shaped, as revealed by the decreasing BWV:BWM ratio (Table 2). Thus as froglets grow into adults, the body becomes better adapted for jumping and leading an arboreal life. Mahanta et al. (1997) showed that a longer femur supporting relatively shorter SV aids the arboreal species to jump from one place to another. We find here that not only the femur, but the tibia also becomes greatly elongated in relation to SV length. However, Mahanta et al. (1997) reports M. ornata as a terrestrial burrowing type, while our observations both in field and laboratory reveal it to be a predominantly arboreal species. Even when kept in captivity, both froglets and adults show a tendency to jump and cling to vertical surfaces. Again, Mahanta et al.

Table 2. Morphometric measurements (in $\mathrm{mm}$ ) of froglet and adult of M. ornata ( $X \pm S D$; range in parenthesis)

\begin{tabular}{|c|c|c|}
\hline Parameters & Froglet & Adult \\
\hline SV & $7.63 \pm 2.16(5.87-10.0)$ & $18.33 \pm 2.02(16.0-19.5)$ \\
\hline TL & $8.98 \pm 3.67(6.0-13.0)$ & - \\
\hline HW & $2.95 \pm 0.32(2.5-3.25)$ & $5.66 \pm 0.58(5.0-6.0)$ \\
\hline $\mathrm{HL}$ & $2.1 \pm 0.39(1.62-2.5)$ & $3.33 \pm 0.52(2.75-3.75)$ \\
\hline BWM & $3.02 \pm 0.25(2.75-3.25)$ & $7.66 \pm 0.58(7.0-8.0)$ \\
\hline BWV & $2.48 \pm 0.41(2.0-2.9)$ & $4.66 \pm 0.58(4.0-5.0)$ \\
\hline$E-N$ & $0.61 \pm 0.13(0.47-0.71)$ & $2.0 \pm 0.0$ \\
\hline S-O & $1.03 \pm 0.12(0.94-1.17)$ & $2.66 \pm 0.58(2.0-3.0)$ \\
\hline S-N & $0.42 \pm 0.25(0.23-0.71)$ & $1.0 \pm 0.0$ \\
\hline I-N & $0.95 \pm 0.02(0.94-0.98)$ & $1.83 \pm 0.29(1.5-2.0)$ \\
\hline $1-0$ & $1.54 \pm 0.16(1.26-1.64)$ & $2.91 \pm 0.14(2.75-3.0)$ \\
\hline$E$ & $0.93 \pm 0.08(0.8-1.0)$ & $2.0 \pm 0.0$ \\
\hline Ty & Indistinct & $1.58 \pm 0.14(1.5-1.75)$ \\
\hline $\mathrm{T}$ & $1.34 \pm 1.5(0.13-3.0)$ & - \\
\hline $\mathrm{F}$ & $2.72 \pm 0.51(2.35-3.29)$ & $9.33 \pm 1.15(8.0-10.0)$ \\
\hline $\mathrm{Tb}$ & $3.05 \pm 0.85(2.39-3.99)$ & $11.16 \pm 1.26(10.0-12.5)$ \\
\hline $\mathrm{Ft}$ & $3.62 \pm 0.98(2.86-4.7)$ & $15.67 \pm 1.53(14.0-17.0)$ \\
\hline $\mathrm{FL}$ & $2.8 \pm 0.54(2.0-3.25)$ & $10.83 \pm 0.76(10.0-11.5)$ \\
\hline HL/HW & $0.7 \pm 0.08(0.6-0.82)$ & $0.59 \pm 0.04(0.55-0.63)$ \\
\hline HL/SV & $0.28 \pm 0.01(0.24-0.36)$ & $0.18 \pm 0.01(0.17-0.19)$ \\
\hline $\mathrm{Tb} / \mathrm{SV}$ & $0.4 \pm 0.01(0.39-0.42)$ & $0.61 \pm 0.04(0.56-0.64)$ \\
\hline FL/SV & $0.38 \pm 0.07(0.32-0.43)$ & $0.59 \pm 0.03(0.56-0.62)$ \\
\hline FT/SV & $0.47 \pm 0.01(0.46-0.49)$ & $0.86 \pm 0.03(0.82-0.88)$ \\
\hline BWV/BWM & $0.81 \pm 0.07(0.73-0.89)$ & $0.61 \pm 0.03(0.57-0.63)$ \\
\hline
\end{tabular}

(1997) have recorded SV: F ratios of 2.63-3.2 in adult and 2.46 in immatures, thereby revealing a relative shortening of the femur as the froglet grows into adult. In contrast, we have measured $\mathrm{SV}: F$ ratios of 1.96 and 2.81 in adults and froglets, respectively, thereby showing a reduction in the length of the body to be supported by femur while jumping, as development from froglet to adult proceeds. Furthermore, the Ft:SV ratio also increases about 1.83 times from froglet to adult (Table 2), and this may be said to be an adaptation ensuring firmer foothold on trunks/ branches of trees and other vertical surfaces. As to whether these differences reflect any subspecific/geographical racial variations between $M$. ornata populations in Orissa and southern Assam, may be worth investigating.

\section{Acknowledgement}

We are grateful to Dr. S.K. Chanda, Zoological Survey of India, Calcutta for identifying the Microhyla specimens. Mithra Dey gratefully acknowledges UGC for financial assistance.

\section{References}

Altig, R. (1970). A key to the tadpoles of the continental United States and Canada. Herpetologica 26: 180-207.

Chanda, S.K. (1994). Anuran (amphibian) fauna of Northeast India. Memoirs of Zoological Survey of India: 143.

Davies, M. and G.F. Watson (1994). Morphology and reproductive Biology of Limnodynastes salmini, L. converxiusculus and Megistolotis lignarius (Anura: Leptodactylidae: Limnodynastinae). Transactions of the Royal Society of South Australia 118(3): 149-169.

Duméril, A.M.C. and G. Bibron (1841). Erpetologic generall ou histoire naturelle complete des Reptiles. Tome 8 Paris 3: 1-192.

Fergusson, H.S. (1904). A list of Travancore batrachians. Journal of the Bombay Natural History Society 15: 499-509.

Mahanta, J.K., S.K. Swain and M.C. Dash (1997). Morphometric relationships in tropical anurans and their relationship to some life history parameters. Journal of the Bombay Natural History Society 94: 276-282.

McCann, C. (1940). A reptile and amphibian miscellany. Journal of the Bombay Natural History Society 42: 45-64.

McDonald, K.R. and M. Davies. (1990). Morphology and biology of the Australian tree frog, Litoria pearsoniana (Copland) (Anura: Hylidae). Transactions of the Royal Society of South Australia 114(3): 145-146.

Meyer, F. (1991). Beobachtungen an Bufo danatensis (Pisanetz, 1978) in der Mongolei (Amphibia, Anura: Bufonidae). Zool. Abh. Mus. Tierkd. Dresden 46(10): 157-164.

Pillai, R.S. and S.K. Chanda (1981). Amphibian fauna of Garo Hills, Meghalaya with description of a new species of Rana. Records of the Zoological Survey of India 79: 159-168.

Thurston, E. (1888). Catalogue of the Batrachia Salientia and Apoda (Frogs, toads and cicilians) of southern India. Bulletin of Madras Government Press 42 (old series).

Tyler, M.J. (1968). Papuan hylid frogs of the genus Hyla. Zool. Verh. Leiden 96: 1-203. 